\title{
Does Tourniquet Time or Pressure Contribute to Intracranial Pressure Increase following Tourniquet Application?
}

\author{
Ahmet Besir Ersagun Tugcugil \\ Department of Anesthesiology and Critical Care, Karadeniz Technical University, Faculty of Medicine, \\ Trabzon, Turkey
}

\section{Significance of the Study}

- In this study, increases in intracranial pressure (ICP) in the early period after tourniquet deflation are associated with tourniquet time but not with tourniquet pressure. We also found that a tourniquet application time of $\geq 67.5$ min was the cut-off value, and this is considered the starting point of the increase in ICP after tourniquet deflation.

\section{Keywords}

Tourniquet · Intracranial pressure · Arterial occlusion pressure Optic nerve sheath diameter

\begin{abstract}
Objective: The aim of this study was to determine whether an early increase in intracranial pressure (ICP) following the deflation of a tourniquet is related to the tourniquet time (TT) or tourniquet pressure (TP) and to identify a safe cut-off value for TT or TP. Materials and Methods: Patients who underwent elective orthopedic lower-extremity surgery under general anesthesia were randomized into 2 groups: group A (inflation with a pneumatic TP of systolic blood pressure + $100 \mathrm{~mm} \mathrm{Hg} ; n=30$ ) and group B (inflation using the arterial occlusion pressure formula; $n=30$ ). The initial and maximum TPs, TT, and sonographic measurements of optic-nerve sheath diameter (ONSD) and end-tidal $\mathrm{CO}_{2}$ values were taken at specific time points ( $15 \mathrm{~min}$ before the induction of anesthesia, just before, and 5, 10, and 15 min after the tourniquet was deflated). Results: The initial and maximum TPs
\end{abstract}

\begin{tabular}{ll}
\hline KARGER & $\begin{array}{l}\text { ( } 2018 \text { The Author(s) Karger } \\
\text { Published by S. Karger AG, Basel Open caccess }\end{array}$ \\
E-Mail karger@karger.com & $\begin{array}{l}\text { This is an Open Access article licensed under the Creative Commons } \\
\text { Attribution-NonCommercial-4.0 International License (CC BY-NC) } \\
\text { (http://www.karger.com/Services/OpenAccessLicense), applicable to } \\
\text { the online version of the article only. Usage and distribution for } \\
\text { commercial purposes requires written permission. }\end{array}$
\end{tabular}

were found to be significantly higher in group A than in group B. At 5 min after the tourniquet deflation, there was a significant positive correlation between $\Pi T$ and ONSD ( $r=$ $0.57, p=0.0001)$. When ONSD $\geq 5 \mathrm{~mm}$ was taken as a standard criterion, the safe cut-off value for the optimal $T T$ was found to be $<67.5 \mathrm{~min}$ (sensitivity $87 \%$ and specificity $59.5 \%$ ). Conclusion: The ICP increase in the early period after tourniquet deflation was well correlated with TT but not with TP. $\Pi$ of $\geq 67.5 \mathrm{~min}$ was found to be the cut-off value and is considered the starting point of the increase in ICP after tourniquet deflation.

(c) 2018 The Author(s) Published by S. Karger AG, Basel

\section{Introduction}

Tourniquets are routinely applied in orthopedic extremity surgery due to their advantages $[1,2]$. The use of a tourniquet in orthopedic interventions provides a bloodless surgical site, providing protection against surgical complications and shortening the operation time, 
and consequently shortening the length of hospital stay [3].

Local and systemic complications that develop secondary to a high cuff pressure and a long duration of tourniquet use include nerve damage, vascular injuries, ischemia/reperfusion injury, and increased intracranial pressure (ICP) $[4,5]$. In recent years, minimal tourniquet inflation pressure has been used instead of traditional tourniquet pressure (TP) values to reduce complications caused by excessive TP. Bloodless surgical fields can be achieved at a much lower pressure than conventional TP by using a method formulated with arterial occlusion pressure (AOP), systolic blood pressure (SBP), and tissue padding coefficient $\left(\mathrm{K}_{\mathrm{TP}}\right)$ values according to the circumference of the extremity $\left(\mathrm{AOP}=[\mathrm{SBP}+10] / \mathrm{K}_{\mathrm{TP}}\right)[6,7]$.

Studies on the relationship between tourniquet-related complications and tourniquet time (TT) have generally involved experimental animal models, and there are a limited number of human studies in the literature $[8,9]$. Studies on healthy volunteers have suggested that the TT should be limited to $2 \mathrm{~h}[1,4,10]$. The risk of systemic complications increases with time, especially in patients with morbid obesity, a history of peripheral vascular surgery, and severe left-ventricular dysfunction, as well as in elderly and trauma patients [1]. A high TP causes more metabolite accumulation in the ischemic area, and during the deflation period, more metabolites are released into the systemic circulation. In particular, the increase in carbon dioxide $\left(\mathrm{CO}_{2}\right)$ from the ischemic metabolic products released during the reperfusion period after the tourniquet is deflated in patients with head trauma and multiple-extremity trauma is significant in ICP. This increase causes cerebral vasodilatation and an increase in cerebral blood flow (CBF). Ultimately, an increase in ICP occurs [11]. The increased ICP following tourniquet application may alter the patient's condition by causing cerebral shift and potential permanent cerebral injury in orthopedic patients with extremity trauma and head trauma.

Although invasive methods are considered the gold standard in ICP monitoring, they are associated with significant risks such as bleeding and infection [12, 13]. Recently, many studies in the literature have shown that the ultrasonographic measurement of optic-nerve sheath diameter (ONSD) is a noninvasive and rapid technique for monitoring ICP changes $[14,15]$. The primary aim of our study was to ascertain whether an early increase in ICP following tourniquet deflation is related to the TT or TP. The secondary aim of our study was to determine a cut-off value of the TT, which is considered an indicator for the increase in ICP in the early period after tourniquet deflation.

\section{Materials and Methods}

The study was carried out in the Orthopedic Operating Theater after obtaining the approval of the local ethics committee at Karadeniz Technical University's Faculty of Medicine, and the written consent of all the patients included in the study. This study included a total of 60 American Society of Anesthesiologists Physical Status Classification (ASA) I-II patients, aged 18-65 years, who were scheduled for elective orthopedic intervention with tourniquet application of a lower extremity.

Patients excluded from this study include those with a known history of orbital trauma, ophthalmic diseases, and surgery, conditions that could cause ICP changes (cerebrovascular events, hemorrhage, intracranial space-occupying tumors, etc.), or coagulopathy, as well as those who refused to participate in the study, had any contraindication to general anesthesia or tourniquet use, or had previous adverse reactions to the medications used in the study.

After the preoperative evaluation, the patients were ready for anesthesia after $8 \mathrm{~h}$ of fasting and monitoring including electrocardiography (ECG) and heart rate (HR), noninvasive mean arterial pressure (MAP), peripheral oxygen saturation $\left(\mathrm{SpO}_{2}\right)$, end-tidal $\mathrm{CO}_{2}\left(\mathrm{EtCO}_{2}\right)$ (Spacelabs Medical, USA), bispectral index (BIS) (Aspect Medical Systems XP, USA), and neuromuscular monitoring. After premedication with $0.03 \mathrm{mg} / \mathrm{kg}$ midazolam and $3 \mathrm{~min}$ of preoxygenation, anesthesia was induced by intravenous administration of $2-3 \mathrm{mg} / \mathrm{kg}$ propofol and $1 \mu \mathrm{g} / \mathrm{kg}$ fentanyl, muscle relaxation achieved with $0.6 \mathrm{mg} / \mathrm{kg}$ rocuronium, and endotracheal intubation carried out when the BIS value reached $<60$. After successful intubation was confirmed, mechanical ventilation was set to achieve a tidal volume of $6-8 \mathrm{~mL} / \mathrm{kg}$ and a respiratory rate of 10-12 min. Anesthesia was maintained with a BIS of 40-60, a total gas flow rate of $4 \mathrm{~L} / \mathrm{min}$ using sevoflurane in a concentration of $1-2 \%$, an $\mathrm{O}_{2} /$ medical air ratio of $1: 1$, a continuous remifentanil infusion of $0.1-0.5 \mu \mathrm{g} / \mathrm{kg} / \mathrm{min}$, and muscle relaxants when needed.

In a total of 60 orthopedic surgical patients, a standard pneumatic tourniquet with an $11-\mathrm{cm}$-wide cuff was placed so that the distal tip was at a distance $15 \mathrm{~cm}$ from the proximal pole of the patella. Computer-assisted randomization was used to assign patients to either group A (inflation with a pneumatic TP of SBP + $100 \mathrm{~mm} \mathrm{Hg} ; n=30$ ) or group B (inflation using the AOP formula; $n=30$ ). A consort flow diagram of the study is shown in Figure 1. Randomization was performed before group assignment using computer-assisted random numbers from www.randomization. com. The allocation list was generated before the study and packed in an envelope. The envelope was opened only when adding a new patient who fulfilled the inclusion criteria.

In the group inflated according to the AOP formula, the equation "SBP + $10 \mathrm{~mm} \mathrm{Hg} / \mathrm{K}_{\mathrm{TP}}$ " was used. The initial SBP was measured, and the corresponding tissue padding coefficient value $\left(\mathrm{K}_{\mathrm{TP}}\right)$ was used [6]. A final TP was achieved by adding $20 \mathrm{~mm} \mathrm{Hg}$ to the AOP value for safety purposes. The tourniquet was inflated after exsanguination of the limb using an Esmarch bandage or elevation of the limb for $3 \mathrm{~min}$. During the operation, the TP was increased by $10 \mathrm{~mm}$ for each $10-\mathrm{mm} \mathrm{Hg}$ increase in the SBP during the measurements performed at 10 -min intervals. If there was an increase in initial TP and SBP, the value obtained was recorded as maximum TP.

Sonographic measurement of ONSD was performed by 2 anesthesiologists experienced in ultrasonography in accordance with 


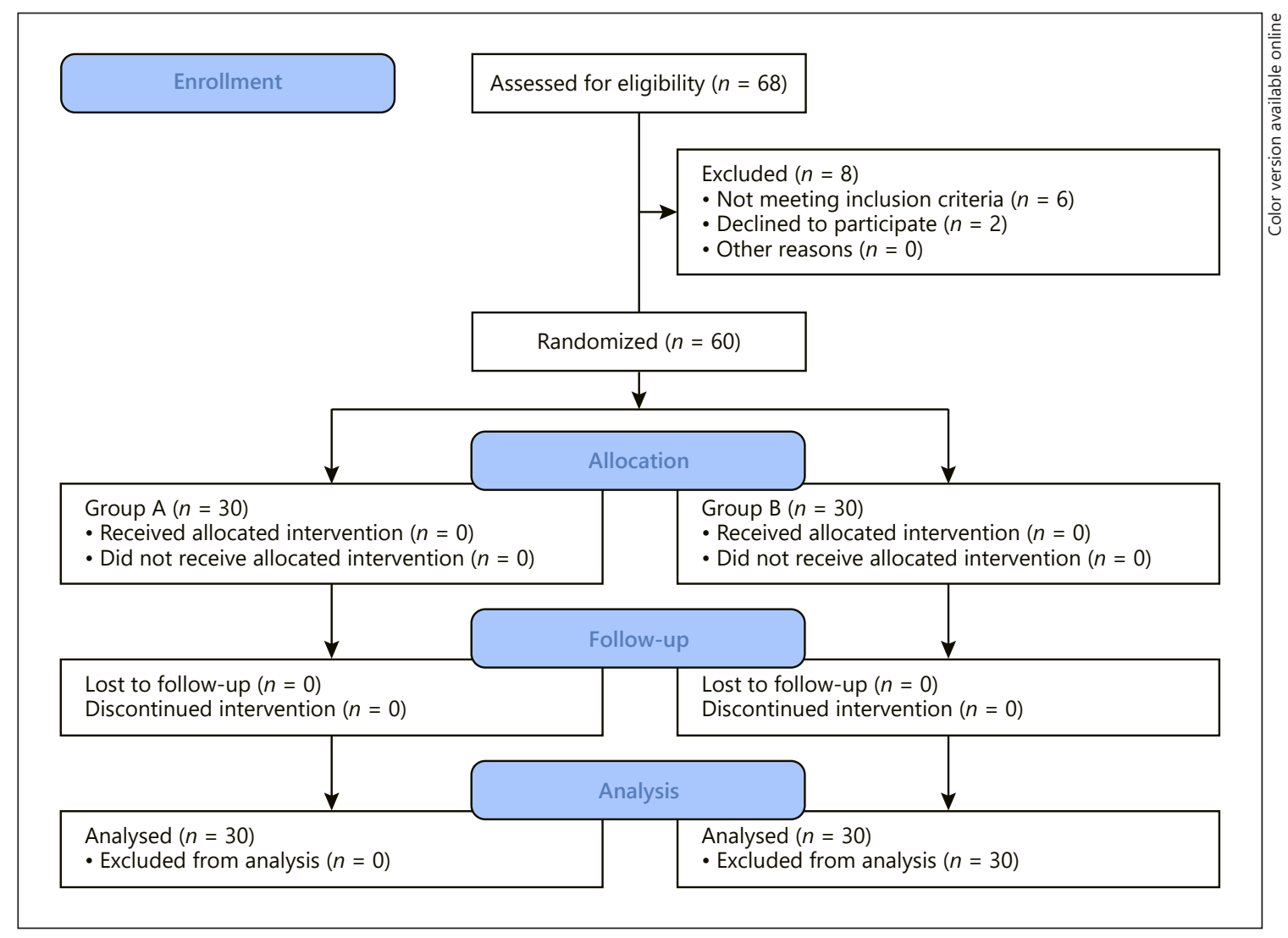

Fig. 1. Consort flow diagram of the study.

studies reported in the literature [16]. Four measurements were performed separately in the transverse and sagittal planes for both eyes. The average of these 4 measurements was accepted as the final value.

The values were recorded separately at 5 different time points: 15 min before the induction of anesthesia $\left(\mathrm{T}_{0}\right)$, immediately before deflating the tourniquet $\left(\mathrm{T}_{\mathrm{i}}\right)$, and 5, 10, and $15 \mathrm{~min}$ after the tourniquet was deflated $\left(\mathrm{Td}_{5}, \mathrm{Td}_{10}\right.$, and $\mathrm{Td}_{15}$, respectively). In addition, the general characteristics, operation, and TT, AOP, and initial and maximum TP of each patient were recorded. At the end of the operation, the surgeon, who was blinded to the TP, rated the performance of the tourniquet as excellent (no blood in the surgical field), good (some blood in the surgical field but not interfering with surgery), or bad (the blood in the surgical field obscured the view), and the results were recorded.

\section{Statistical Analyses}

The Statistical Package for Social Sciences (SPSS Inc., Chicago, IL, USA) v23.0 was used for the statistical analysis of the data obtained in the study. Descriptive statistical expressions (frequency, mean, and standard deviation [SD]) were used to assess the data. For the comparison of descriptive values, the $\chi^{2}$ test was used. Normal distribution of values was assessed using the KolmogorovSmirnow test, and Student's $t$ test was used for all measures fulfilling the parametric test hypothesis. Repeated-measures ANOVA and the Bonferroni correction were preferred for comparison of the parameters of the 2 groups. The Pearson correlation analysis was used for intermeasure comparisons.

Receiver-operating characteristics (ROC) curves were generated to determine the ONSD and the cut-off point of $\mathrm{EtCO}_{2}$ measurements in patients with a TT of $\geq 60 \mathrm{~min}$. ROC analysis was used to determine the cut-off values in diagnostic tests. Sensitivity, specificity, and positive and negative predictive values (PPV and NPV) were calculated according to the cut-off. The results were within the $95 \%$ confidence interval $(\mathrm{CI})$, with a significance level of $p<0.05$.

The following values were used for the calculation of sample size. A total of 60 cases ( 23 from the test positive group [ONSD $\geq 5$ $\mathrm{mm}$ at $5 \mathrm{~min}$ after tourniquet deflation] and 37 from the negative group [ONSD $<5 \mathrm{~mm}$ at $5 \mathrm{~min}$ after tourniquet deflation]) achieved a $53 \%$ power to detect a difference of 0.1500 between the area under the ROC curve (AUC) under the null hypothesis (i.e., patients having a short operation time would not have a high ICP) of 0.6500, and an AUC under the alternative hypothesis (i.e., patients having a long operation time would have a high ICP) of 0.8000 using a two-sided $z$ test at a significance level of 0.05000 . The data are discrete (rating scale) responses. The AUC is computed between false-positive rates of 0.000 and 1.000 . The ratio of the SD of the responses in the negative group to that of the responses in the positive group was 1.000 . 
Table 1. General characteristics of patients and intraoperative data

\begin{tabular}{|c|c|c|c|}
\hline Parameter & $\begin{array}{l}\text { Group A } \\
(n=30)\end{array}$ & $\begin{array}{l}\text { Group B } \\
(n=30)\end{array}$ & $p$ value \\
\hline Age, years & $34.3 \pm 16.8$ & $34.1 \pm 13.1$ & $0.959^{\mathrm{a}}$ \\
\hline Gender (male/female) & $21 / 9$ & $15 / 15$ & $0.118^{\mathrm{b}}$ \\
\hline BMI & $24.6 \pm 3.1$ & $24.2 \pm 2.8$ & $0.556^{\mathrm{a}}$ \\
\hline ASA I/II & $23 / 7$ & $21 / 9$ & $0.771^{b}$ \\
\hline Operation time, $\min$ & $87.0 \pm 28.1$ & $91.8 \pm 31.4$ & $0.535^{\mathrm{a}}$ \\
\hline Tourniquet time, min & $75.5 \pm 27.6$ & $72.3 \pm 26.2$ & $0.643^{\mathrm{a}}$ \\
\hline Initial SBP, mm Hg & $109.6 \pm 6.3$ & $108.5 \pm 5.3$ & $0.495^{\mathrm{a}}$ \\
\hline Initial tourniquet pressure, $\mathrm{mm} \mathrm{Hg}$ & $221.2 \pm 12.4$ & $180.5 \pm 10.2$ & $0.0001^{\mathrm{a}}$ \\
\hline Maximal tourniquet pressure, $\mathrm{mm} \mathrm{Hg}$ & $230.1 \pm 15.9$ & $187.7 \pm 11.9$ & $0.0001^{\mathrm{a}}$ \\
\hline Satisfaction of surgeon (I/II/III) & $27 / 3 / 0$ & $26 / 3 / 1$ & $0.601^{\mathrm{b}}$ \\
\hline \multicolumn{4}{|l|}{ Surgical procedures } \\
\hline Arthroscopic knee surgery & $26(86 \%)$ & $25(83 \%)$ & \multirow[t]{3}{*}{$<0.05^{\mathrm{b}}$} \\
\hline Removal of internal fixation & $2(7 \%)$ & $3(10 \%)$ & \\
\hline Achill tendon repair & $2(7 \%)$ & $2(7 \%)$ & \\
\hline
\end{tabular}

\section{Results}

The general characteristics and intraoperative data of the patients are shown in Table 1 . There was no significant difference between the groups in terms of $\mathrm{HR}, \mathrm{MAP}, \mathrm{SpO}_{2}$, $\mathrm{BIS}$, and ONSD and $\mathrm{EtCO}_{2}$ values $(p>0.05)$ (Table 2$)$. The initial and maximum TPs were found to be significantly higher in group A than in group B ( $p=0.0001$ for all).

There was a significant positive correlation of TT and the ONSD and $\mathrm{EtCO}_{2}$ measurements at 5 min after tourniquet deflation $(r=0.57, p=0.0001$ for ONSD and $r=$ $0.35, p=0.006$ for $\left.\mathrm{EtCO}_{2}\right)$. However, there was no statistically significant correlation between maximum TP and the ONSD and $\mathrm{EtCO}_{2}$ measurements at this time point.

Taking ONSD $\geq 5 \mathrm{~mm}$ as a standard criterion, ROC analysis was performed to determine the TT cut-off value when the ONSD was $\geq 5 \mathrm{~mm}$. The AUC was 0.82 (95\% CI $0.71-0.93)$ in the ROC created, and the cut-off value for the optimal TT was $\geq 67.5 \mathrm{~min}$ (sensitivity $87 \%$, specificity $59.5 \%$, PPV $57.1 \%$, and NPV $88 \%$; Fig. 2).

The evaluation of all cases showed a significant difference in TT value between the groups assigned an ONSD value of $\geq 5 \mathrm{~mm}$ and $<5 \mathrm{~mm}$ at $5 \mathrm{~min}$ after tourniquet deflation $(92.7 \pm 24.4$ and $62.3 \pm 21.1$, respectively; $p=$ 0.0001 ; Fig. 3). During the same period, there was no significant difference in maximum TP between the groups $(207.86 \pm 26.2$ and $210.65 \pm 24.8$, respectively; $p=0.684)$.
During the study, there were no complications associated with ultrasonographic ONSD measurements.

\section{Discussion}

Our major finding was that the increase in ICP in the early period after tourniquet deflation (after $5 \mathrm{~min}$ ) was associated with TT but not with TP. We also found that a TT of $\geq 67.5 \mathrm{~min}$ was the cut-off value and is considered the starting point of the increase in ICP after tourniquet deflation.

In orthopedic surgery, tourniquets are often used to reduce hemorrhage in the operative field, improve the visualization of important structures, and expedite the surgical procedure [3]. All pneumatic tourniquets including the new generation of automated devices can lead to a wide range of complications, from minor and self-limiting to life-threatening [1].

Local complications may be due to either direct pressure to, or tissue ischemia in, the underlying tissues, whereas systemic effects are usually associated with TT and ischemia-reperfusion following tourniquet deflation [1]. It has been recommended that TT be limited to $2 \mathrm{~h}$ in human studies due to the increase in postoperative complications caused by an extended TT [10]. Investigating the relationship between TT and postoperative complica- 
Table 2. Intraoperative variables

\begin{tabular}{|c|c|c|c|}
\hline Parameter & Group A & Group B & $p$ value \\
\hline \multicolumn{4}{|l|}{$\mathrm{T}_{0}$} \\
\hline MAP, $\mathrm{mm} \mathrm{Hg}$ & $92.3 \pm 10.3$ & $92.2 \pm 10.6$ & 0.835 \\
\hline $\mathrm{HR}, \mathrm{bpm}$ & $74.5 \pm 11.7$ & $74.3 \pm 5.8$ & 0.912 \\
\hline Saturation, \% & $97.7 \pm 1.6$ & $97.6 \pm 0.9$ & 0.903 \\
\hline BIS & $97.7 \pm 0.6$ & $97.7 \pm 0.5$ & 0.814 \\
\hline $\mathrm{EtCO}_{2}, \mathrm{~mm} \mathrm{Hg}$ & 0 & 0 & - \\
\hline ONSD, $\mathrm{mm}$ & $3.7 \pm 0.02$ & $3.7 \pm 0.02$ & 0.768 \\
\hline \multicolumn{4}{|l|}{$\mathrm{T}_{\mathrm{i}}$} \\
\hline MAP, mm Hg & $89.7 \pm 9.01$ & $90.7 \pm 6,6$ & 0.626 \\
\hline $\mathrm{HR}, \mathrm{bpm}$ & $77.5 \pm 12.9$ & $77.2 \pm 11.2$ & 0.924 \\
\hline Saturation, \% & $98.5 \pm 0.9$ & $98.6 \pm 1.4$ & 0.911 \\
\hline BIS & $53.1 \pm 3.9$ & $52.2 \pm 3.2$ & 0.311 \\
\hline $\mathrm{EtCO}_{2}, \mathrm{~mm} \mathrm{Hg}$ & $32.5 \pm 0.9$ & $33.1 \pm 1.6$ & 0.097 \\
\hline ONSD, $\mathrm{mm}$ & $3.9 \pm 0.02$ & $3.7 \pm 0.03$ & 0.061 \\
\hline \multicolumn{4}{|l|}{$\mathrm{T}_{\mathrm{d} 5}$} \\
\hline MAP, mm Hg & $76.3 \pm 10.4$ & $78.8 \pm 9.7$ & 0.332 \\
\hline $\mathrm{HR}, \mathrm{bpm}$ & $74.7 \pm 8.9$ & $72.8 \pm 6.9$ & 0.351 \\
\hline Saturation, \% & $98.9 \pm 0.9$ & $99.1 \pm 1.0$ & 0.686 \\
\hline BIS & $50.2 \pm 4.5$ & $49.1 \pm 3.4$ & 0.293 \\
\hline $\mathrm{EtCO}_{2}, \mathrm{~mm} \mathrm{Hg}$ & $41.1 \pm 3.1$ & $40.4 \pm 3.3$ & 0.252 \\
\hline ONSD, mm & $4.8 \pm 0.05$ & $4.7 \pm 0.04$ & 0.618 \\
\hline \multicolumn{4}{|l|}{$\mathrm{T}_{\mathrm{d} 10}$} \\
\hline MAP, mm Hg & $78.5 \pm 11.8$ & $78.8 \pm 7.5$ & 0.906 \\
\hline HR, bpm & $73.2 \pm 7.3$ & $70.2 \pm 6.9$ & 0.108 \\
\hline Saturation, \% & $99.0 \pm 0.7$ & $99.2 \pm 0.9$ & 0.532 \\
\hline BIS & $51.9 \pm 3.9$ & $51.6 \pm 4.3$ & 0.781 \\
\hline $\mathrm{EtCO}_{2}, \mathrm{~mm} \mathrm{Hg}$ & $35.6 \pm 0.9$ & $35.2 \pm 1.6$ & 0.227 \\
\hline ONSD, $\mathrm{mm}$ & $4.2 \pm 0.03$ & $4.1 \pm 0.04$ & 0.710 \\
\hline \multicolumn{4}{|l|}{$\mathrm{T}_{\mathrm{d} 15}$} \\
\hline MAP, mm Hg & $79.7 \pm 10.8$ & $80.6 \pm 7.7$ & 0.702 \\
\hline $\mathrm{HR}, \mathrm{bpm}$ & $74.6 \pm 7.6$ & $72.1 \pm 7.2$ & 0.196 \\
\hline Saturation, \% & $98.9 \pm 0.8$ & $99.2 \pm 0.9$ & 0.145 \\
\hline BIS & $52.7 \pm 3.9$ & $51.8 \pm 3.6$ & 0.362 \\
\hline $\mathrm{EtCO}_{2}, \mathrm{~mm} \mathrm{Hg}$ & $34.1 \pm 1.7$ & $33.6 \pm 1.3$ & 0.205 \\
\hline ONSD, $\mathrm{mm}$ & $3.8 \pm 0.02$ & $3.8 \pm 0.03$ & 0.959 \\
\hline
\end{tabular}

Data are expressed as mean $\pm \mathrm{SD}$. MAP, mean arterial pressure, $\mathrm{HR}$, heart rate; $\mathrm{BIS}$, bispectral index; $\mathrm{EtCO}_{2}$, end-tidal carbon dioxide; ONSD, optic-nerve sheath diameter. $p>0.05$, Student's $t$ test was used for comparison.

tions in arthroplastic knee surgery, Olivecrona et al. [17] found an increase in postoperative complications including wound leakage, local injury due to TP, nerve damage, compartment syndrome, deep venous thrombosis, and pulmonary embolism with every 10 -min increment in TT.

The use of the lowest effective inflation pressure is aimed at minimizing the local complications associated with tourniquet use, such as nerve damage. Orthopedic

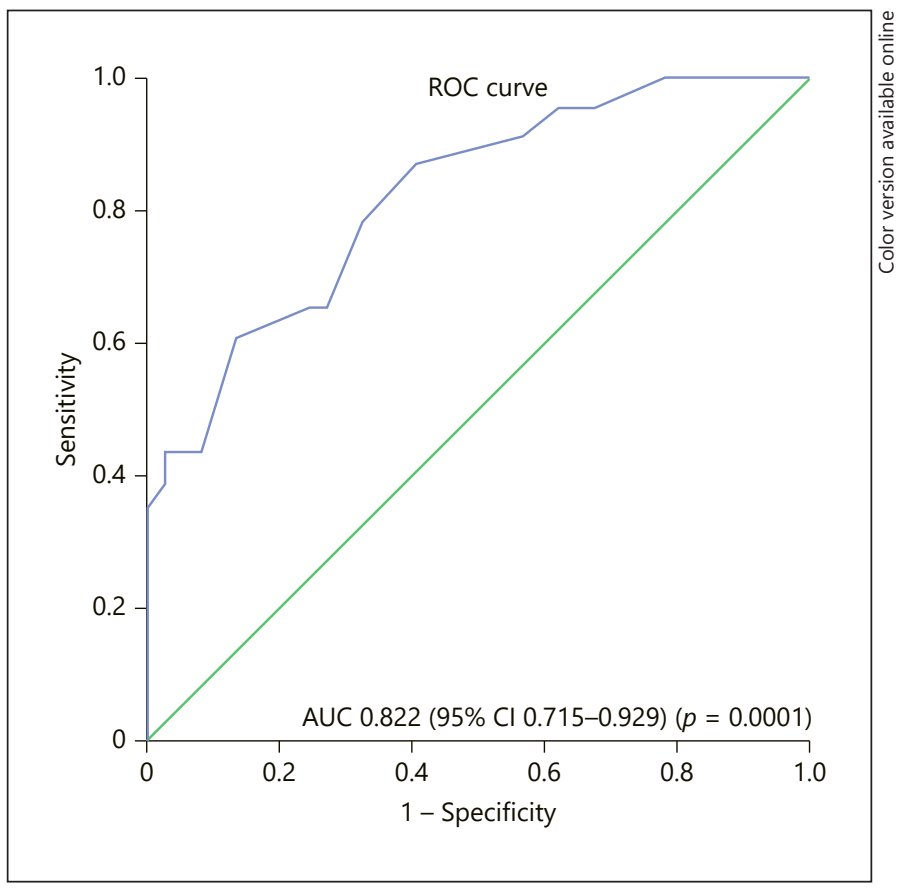

Fig. 2. The ROC curve created for the tourniquet time at $5 \mathrm{~min}$ after tourniquet deflation.

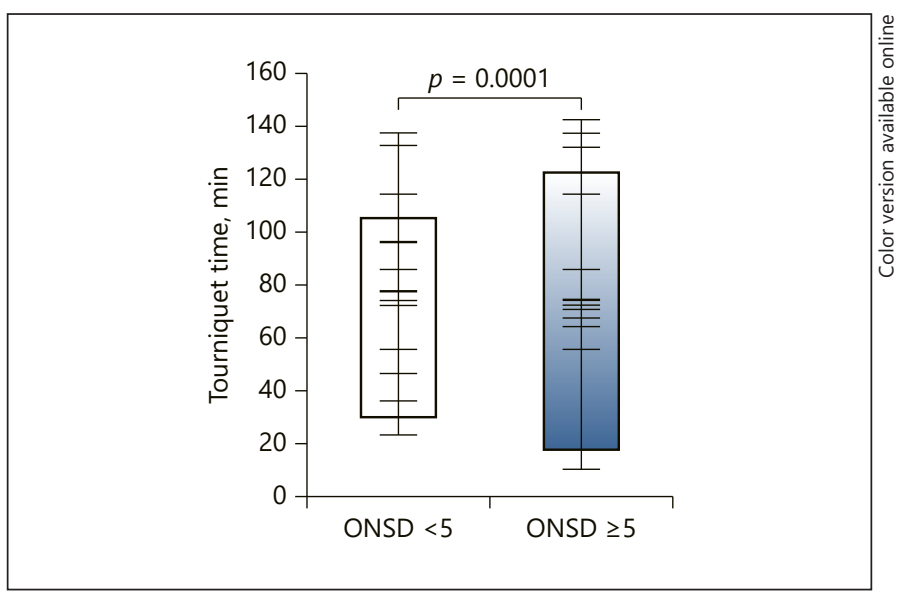

Fig. 3. Tourniquet time of the groups assigned ONSD values of $\geq 5$ $\mathrm{mm}$ and $<5 \mathrm{~mm}$ at $5 \mathrm{~min}$ after tourniquet deflation.

surgeons often apply a constant inflation pressure (typically, $250 \mathrm{~mm} \mathrm{Hg}$ for the upper arm and $300 \mathrm{~mm} \mathrm{Hg}$ for the thigh), or a constant pressure over the systolic arterial pressure (typically, $+100 \mathrm{~mm} \mathrm{Hg}$ for the upper arm and $100-150 \mathrm{~mm} \mathrm{Hg}$ for the thigh) [18].

When compared to conventional methods, studies have shown that the TP is reduced by $19-42 \%$ according 
to the AOP calculated just prior to surgery [19]. It has also been determined that these pressures are sufficient to provide a bloodless surgical site [6]. Olivecrona et al. [20] compared tourniquet applications by SBP and AOP and found that an adequate bloodless surgical site could be provided with lower pressure and that the postoperative complication rate was lower in patients who underwent the AOP technique. In our study, we found that TP at the beginning of the operation and maximum TP were significantly lower in group $\mathrm{B}$ than in group $\mathrm{A}$, and that there was no difference between the groups in terms of satisfaction with the surgical field. In addition, we found there was no difference between the groups in term of ICP.

The metabolic effects of tourniquet use are usually due to ischemia-reperfusion injury after tourniquet deflation. After 1-2 h of ischemia, a modest increase in arterial plasma potassium, lactate levels, oxygen consumption, and $\mathrm{CO}_{2}$ production, and a transient decrease in arterial $\mathrm{pH}$ levels occur following tourniquet deflation [21,22]. The potent vasodilator effect on the veins of elevated $\mathrm{CO}_{2}$ following tourniquet deflation results in a $50 \%$ increase in middle cerebral artery blood flow velocity, which peaks after approximately $2-4 \mathrm{~min}$ and returns to baseline value within 8-10 $\min$ [23-25].

There are a limited number of studies in the literature evaluating ICP changes after tourniquet deflation. Eldridge and Williams [26] reported that an increase in $\mathrm{EtCO}_{2}$ level was accompanied by an increase in ICP after tourniquet deflation, according to invasive ICP monitoring inserted in the preoperative period in a patient with traumatic brain injury who had a tourniquet applied during orthopedic surgery. With tourniquet deflation, the concomitant increase in $\mathrm{CO}_{2}$ level can cause a dangerous increase in ICP. This situation may have serious consequences in patients with traumatic brain injury or an intracranial space-occupying lesion.

In ICP monitoring, the intraventricular catheter technique is accepted as the gold standard despite being invasive. Therefore, in our study, we determined ICP changes after tourniquet deflation using serial ultrasonographic ONSD measurement, which is a noninvasive, safe, and rapid technique for showing ICP changes. Based on results reported in other studies, the optimal cut-off value of ONSD for predicting intracranial hypertension ranges from 5.0 to $5.9 \mathrm{~mm}$ [27-29]. We therefore chose an ONSD cut-off value of $5 \mathrm{~mm}$ in our study.

We determined that ICP increase due to the increase of $\mathrm{CO}_{2}$ associated with ischemia-reperfusion, especially in the early period after tourniquet deflation, was not affected by TP but was correlated with TT. A review of the literature did not reveal any studies on cut-off point and onset of ICP increase ( $>5 \mathrm{~mm}$ ) or on TT and TP. In our study, the ONSD value at the point when the ICP increase started 5 min after tourniquet deflation was found to be correlated with TT but not with TP. It should be taken into consideration that the ICP increase may already start in the early period following tourniquet deflation after a TT exceeding $67.5 \mathrm{~min}$ in patients with an intracranial space-occupying lesion or traumatic brain injury who undergo tourniquet application of a lower extremity.

The most important limitation of our study was the use of noninvasive, serial ultrasonographic ONSD measurements because of the potential for ethical problems related to surgical intervention, even though invasive methods that directly measure ICP values are the gold standard. Additionally, the sample size should be larger in order to obtain more precise results for determining a cut-off value for the TT, which is the limit of the ICP increase. The third limitation of the study was its low power.

\section{Conclusion}

(1) Does TT or TP cause ICP increase after pneumatic tourniquet deflation in lower-extremity surgery? (2) What is a safe cut-off value for TT or TP? In this study, we found that the increase in ICP in the early period after tourniquet deflation was associated with TT but not with TP. We also believe that clinicians should be cautious about the start of ICP increase after tourniquet deflation when the TT exceeds $67.5 \mathrm{~min}$.

\section{Acknowledgments}

The authors thank Suleyman Guven from the Department of Obstetrics and Gynecology, Faculty of Medicine, Karadeniz Technical University, Trabzon, Turkey, for her help with the statistics and her support for this study.

References

Med Princ Pract 2019;28:16-22

1 Kam PC, Kavanagh R, Yoong FF. The arterial tourniquet: pathophysiological consequences and anaesthetic implications. Anaesthesia. 2001 Jun;56(6):534-45.

2 Smith TO, Hing CB. Is a tourniquet beneficial in total knee replacement surgery? A metaanalysis and systematic review. Knee. 2010 Mar;17(2):141-7.

3 Estebe JP, Davies JM, Richebe P. The pneumatic tourniquet: mechanical, ischaemia-reperfusion and systemic effects. Eur J Anaesthesiol. 2011 Jun;28(6):404-11. 
4 Noordin S, McEwen JA, Kragh JF Jr, Eisen A, Masri BA. Surgical tourniquets in orthopaedics. J Bone Joint Surg Am. 2009 Dec;91(12): 2958-67.

5 Sparling RJ, Murray AW, Choksey M. Raised intracranial pressure associated with hypercarbia after tourniquet release. Br J Neurosurg. 1993;7(1):75-7.

6 Tuncalı B, Boya H, Kayhan Z, Araç Ş, Çamurdan MA. Clinical utilization of arterial occlusion pressure estimation method in lower limb surgery: effectiveness of tourniquet pressures. Acta Orthop Traumatol Turc. 2016; 50(2):171-7.

7 Tuncali B, Karci A, Tuncali BE, Mavioglu O, Ozkan M, Bacakoglu AK, et al. A new method for estimating arterial occlusion pressure in optimizing pneumatic tourniquet inflation pressure. Anesth Analg. 2006 Jun;102(6) $1752-7$.

8 Nitz AJ, Matulionis DH. Ultrastructural changes in rat peripheral nerve following pneumatic tourniquet compression. J Neurosurg. 1982 Nov;57(5):660-6.

9 Pedowitz RA, Gershuni DH, Schmidt AH, Fridén J, Rydevik BL, Hargens AR. Muscle injury induced beneath and distal to a pneumatic tourniquet: a quantitative animal study of effects of tourniquet pressure and duration. J Hand Surg Am. 1991 Jul;16(4):610-21.

10 Fitzgibbons PG, Digiovanni C, Hares S, Akelman E. Safe tourniquet use: a review of the evidence. J Am Acad Orthop Surg. 2012 May; 20(5):310-9.

11 Hirst RP, Slee TA, Lam AM. Changes in cerebral blood flow velocity after release of intraoperative tourniquets in humans: a transcranial Doppler study. Anesth Analg. 1990 Nov; 71(5):503-10.
12 The Brain Trauma Foundation. The Brain Trauma Foundation. The American Association of Neurological Surgeons. The Joint Section on Neurotrauma and Critical Care. Recommendations for intracranial pressure monitoring technology. J Neurotrauma. 2000 Jun-Jul;17(6-7):497-506.

13 Wilberger JE Jr. Outcomes analysis: intracranial pressure monitoring. Clin Neurosurg. 1997;44:439-48.

14 Rajajee V, Vanaman M, Fletcher JJ, Jacobs TL. Optic nerve ultrasound for the detection of raised intracranial pressure. Neurocrit Care. 2011 Dec;15(3):506-15.

15 Liu D, Li Z, Zhang X, Zhao L, Jia J, Sun F, et al. Assessment of intracranial pressure with ultrasonographic retrobulbar optic nerve sheath diameter measurement. BMC Neurol. 2017 Sep;17(1): 188.

16 Geeraerts T, Merceron S, Benhamou D, Vigué B, Duranteau J. Non-invasive assessment of intracranial pressure using ocular sonography in neurocritical care patients. Intensive Care Med. 2008 Nov;34(11):2062-7.

17 Olivecrona C, Lapidus LJ, Benson L, Blomfeldt R. Tourniquet time affects postoperative complications after knee arthroplasty. Int Orthop. 2013 May;37(5):827-32.

18 Deloughry JL, Griffiths R. Arterial tourniquets. Continuing Education in Anesthesia. Crit Care Pain (Ind Ed) 2009;2:64-8.

19 Younger AS, McEwen JA, Inkpen K. Wide contoured thigh cuffs and automated limb occlusion measurement allow lower tourniquet pressures. Clin Orthop Relat Res. 2004 Nov; 428:286-93

20 Olivecrona C, Blomfeldt R, Ponzer S, Stanford BR, Nilsson BY. Tourniquet cuff pressure and nerve injury in knee arthroplasty in a bloodless field: a neurophysiological study. Acta Orthop. 2013 Apr;84(2):159-64.

21 Modig J, Kolstad K, Wigren A. Systemic reactions to tourniquet ischaemia. Acta Anaesthesiol Scand. 1978;22(6):609-14.
22 Hoka S, Yoshitake J, Arakawa S, Ohta K, Yamaoka A, Goto T. VO2 and VCO2 following tourniquet deflation. Anaesthesia. 1992 Jan; 47(1):65-8.

23 Kadoi Y, Ide M, Saito S, Shiga T, Ishizaki K, Goto F. Hyperventilation after tourniquet deflation prevents an increase in cerebral blood flow velocity. Can J Anaesth. 1999 Mar;46(3): 259-64.

24 Lam AM, Slee T, Hirst R, Cooper JO, Pavlin EG, Sundling N. Cerebral blood flow velocity following tourniquet release in humans. Can J Anaesth. 1990 May;37(4 Pt 2):S29.

25 Doblar DD, Frenette L, Poplawski S, Gelman S, Boyd G, Ranjan D, et al. Middle cerebral artery transcranial Doppler velocity monitoring during orthotopic liver transplantation: changes at reperfusion-a report of six cases. J Clin Anesth. 1993 Nov-Dec;5(6):479-85.

26 Eldridge PR, Williams S. Effect of limb tourniquet on cerebral perfusion pressure in a head-injured patient. Anaesthesia. 1989 Dec; 44(12):973-4.

27 Kimberly HH, Shah S, Marill K, Noble V. Correlation of optic nerve sheath diameter with direct measurement of intracranial pressure. Acad Emerg Med. 2008 Feb;15(2):2014.

28 Geeraerts T, Launey Y, Martin L, Pottecher J, Vigué B, Duranteau J, et al. Ultrasonography of the optic nerve sheath may be useful for detecting raised intracranial pressure after severe brain injury. Intensive Care Med. 2007 Oct;33(10):1704-11.

29 Moretti R, Pizzi B. Optic nerve ultrasound for detection of intracranial hypertension in intracranial hemorrhage patients: confirmation of previous findings in a different patient population. J Neurosurg Anesthesiol. 2009 Jan; 21(1):16-20. 